This item was submitted to Loughborough's Research Repository by the author.

Items in Figshare are protected by copyright, with all rights reserved, unless otherwise indicated.

\title{
Airline market power and intertemporal price dispersion
}

PLEASE CITE THE PUBLISHED VERSION

PUBLISHER

(c) Loughborough University

VERSION

AM (Accepted Manuscript)

LICENCE

CC BY-NC-ND 4.0

REPOSITORY RECORD

Gaggero, Alberto A., and Claudio Piga. 2019. "Airline Market Power and Intertemporal Price Dispersion". figshare. https://hdl.handle.net/2134/5141. 
This item was submitted to Loughborough's Institutional Repository (https://dspace.lboro.ac.uk/) by the author and is made available under the following Creative Commons Licence conditions.

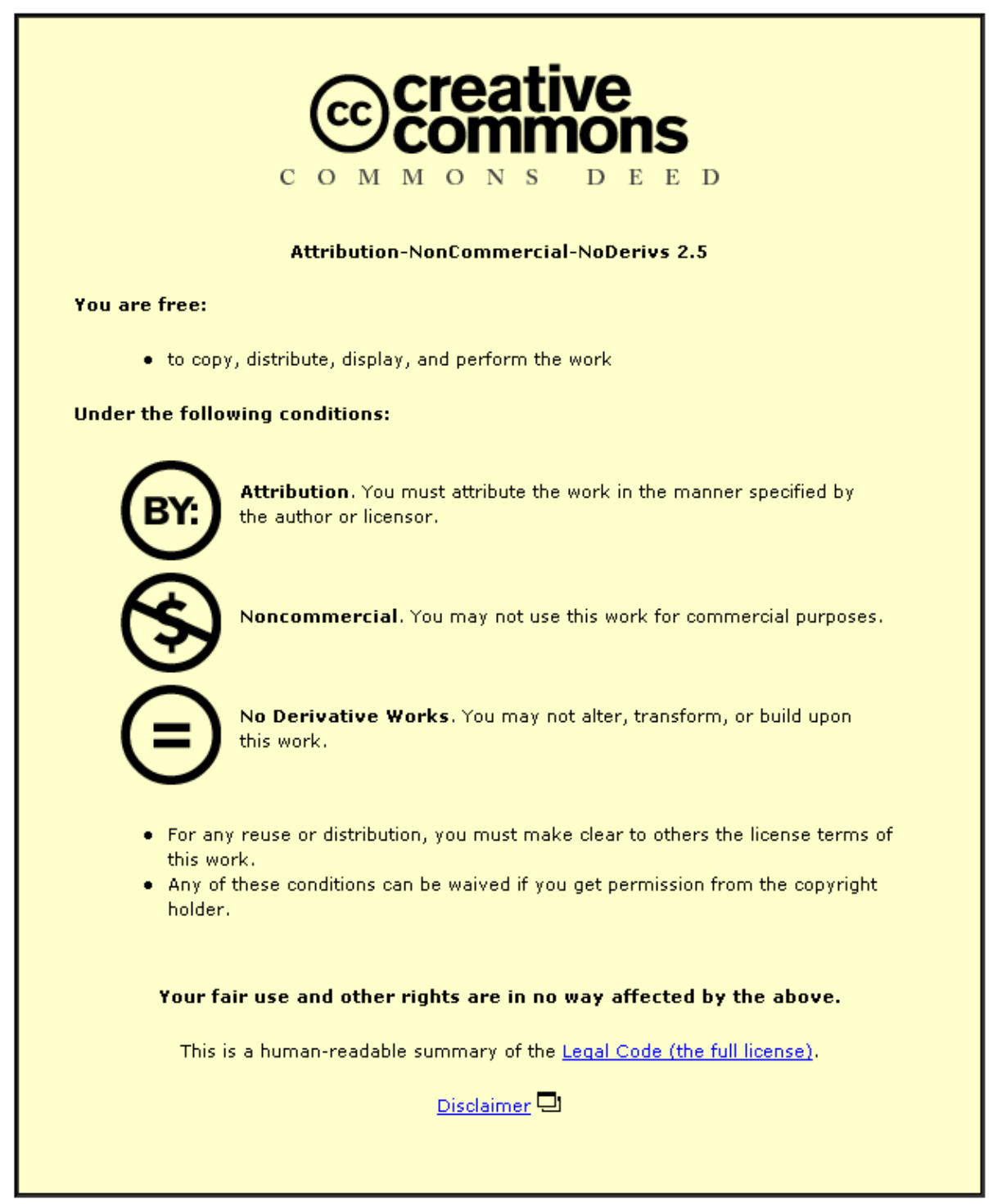

For the full text of this licence, please go to: http://creativecommons.org/licenses/by-nc-nd/2.5/ 
ISSN 1750-4171

\section{DEPARTMENT OF ECONOMICS}

DISCUSSION PAPER SERIES

\section{Airline Market Power and Intertemporal Price Dispersion}

Alberto A. Gaggero

Claudio A. Piga

\section{WP 2009 - 10}

Department of Economics Loughborough University

Loughborough

LE11 3TU United Kingdom

Tel: + 44 (0) 1509222701

Fax: + 44 (0) 1509223910

http://www.lboro.ac.uk/departments/ec 


\title{
Airline Market Power and Intertemporal Price Dispersion
}

\author{
Alberto A. Gaggero* \\ University of Essex \\ Claudio A. Piga \\ Loughborough University and \\ RCEA, Rimini, Italy
}

July 1, 2009

\begin{abstract}
This paper analyzes the empirical relationship between market structure and price dispersion in the airline markets connecting the UK and the Republic of Ireland. Price dispersion is measured by a number of inequality indexes, calculated using fares posted on the Internet at specific days before takeoff. We find a negative correlation between market dominance and price dispersion; thus competition appears to hinder the airlines' ability to price discriminate to exploit consumers' heterogeneity in booking time preferences. Moreover, in the Christmas and Easter periods of high demand, fares are less dispersed, possibly because airlines target a less heterogenous set of consumers.
\end{abstract}

JEL Classification: D43, L10, L93.

Keywords: Intertemporal pricing, competition, price dispersion.

\footnotetext{
${ }^{*}$ Corresponding Author: Department of Economics, University of Essex, Wivenhoe Park, Colchester CO4 3SQ, United Kingdom. Tel: +44 (0)120 6874468 Email: aagagg@essex.ac.uk; URL: http://privatewww.essex.ac.uk/ ^aagagg. We wish to thank Holger Breinlich, Marco Francesconi, Pierre Régibeau, Maxim Sinitsyn, George Symeonidis and Domenico Tabasso. Piga gratefully acknowledges receipt of the British Academy Research Grant SG-45975 and financial support from the Leverhulme Trust Research Fellowship Grant 2007/22 .
} 


\section{Introduction}

Airline pricing represents perhaps the most common violation of the law of one price. Borenstein and Rose (1994) were the first to show that the expected difference in price paid by two randomly selected passengers on a U.S. route is about $36 \%$ of the airline's mean price on the route. Other studies have derived alternative estimates highlighting an increasing trend in the amount of dispersion characterizing the U.S. airline markets (Hayes and Ross, 1998, Gerardi and Shapiro, 2009). The exclusive use of the Internet as a marketing and distribution channel made by the largest Low Cost airlines operating in the European markets appears to have intensified this phenomenon (Piga and Bachis, 2007).

Fare dispersion arises because airlines engage in price discrimination strategies, which consist in dividing passengers according to their price elasticity and charging them a different fare. ${ }^{1}$ The keys to identify and hence segment passengers can be various: advance purchase requirement, Saturday night stay over, frequent flyer programme (Stavins, 2001). Among all these categories, this paper focuses on the price discrimination based on how many days in advance passengers are willing to book their flight and to the consequent price dispersion that is generated. We will refer to this type of price dispersion as Intertemporal Price Dispersion (IPD) and define it as the dispersion which arises when passengers are charged a different fare according to their different booking day preferences.

Such a segmentation strategy may work only if passengers' preferences are heterogenous, which may be induced by a different motivation to travel. Very early bookers are those who need to reach a specific destination and have very little flexibility on their departure date: their demand is thus slightly inelastic and they are willing to pay a moderately high price to secure a place on a specific plane. ${ }^{2}$ Earlyintermediate bookers are normally those who do not fix their departure day ex-ante and shop around across different departure days and destinations: this substitutability makes their demand highly elastic. ${ }^{3}$ Finally, last-minute bookers are generally those whose choice of destinations and travel dates are fixed, so that they are more likely to be willing to pay a high fare. ${ }^{4}$

\footnotetext{
${ }^{1}$ Beside price discrimination there are also other sources of price dispersion. Under stochastic demand pricing, for example, airlines adjust fare as demand is revealed through time. Because capacity is fixed in advance, the amount of the fare highly depends on the probability that future demand exceeds capacity and on the latter's expected shadow cost. This pricing strategy may explain some of the intertemporal price variation in a given flight. Under systematic peak load pricing, airlines charge higher fares during the peaks of demand and lower fares during off-peaks. For this reason business routes typically have higher fares during the week and lower fares during the weekend, resulting in an overall high degree of price dispersion on the route.

${ }^{2}$ Think, for instance, of a family planning the Summer or Winter holiday, something which is generally done well in advance of departure.

3 This could correspond to the market for short-term breaks.

${ }^{4}$ This market segment is typically associated with passengers traveling for business purposes.
} 
The aim of this paper is to study empirically how such IPD practice can be influenced by the intensity of competition on a given route. In principle we can distinguish two opposite effects, which we call "monopoly effect" and "brand effect". 5 The monopoly effect arises when a carrier can price over the marginal cost according to its degree of market power. Under monopoly the firm is able to markup its product with no concern about competitors undercutting their prices; under perfect competition the firm, instead, prices at its marginal cost to retain its customers. Therefore, in a market between these two polar cases, a lower degree of market power should reduce the possibilities for the firm to charge different prices to different consumers. In particular, the monopoly effect suggests that an increase in competition lowers the markup on the price inelastic (business) passengers to a level more in line with the corresponding level of fares charged to price elastic (leisure) passengers. The reduced ability to price discriminate leads to a flatter intertemporal distribution of fares and, therefore, to less price dispersion.

The brand effect depends on the fact that imperfectly competitive markets are multi-product or, more generally, multi-brand markets with heterogeneity in the cross-price elasticities of demand. For this reason consumers may be segmented according to their brand preferences. If we assume that the price inelastic passengers, who represent the upper tail of the fare distribution, are more brand loyal than price elastic passengers, who represent the lower tail of the fare distribution, then increased competition reduces the markup on the lower tail to a larger extent than on the higher tail. ${ }^{6}$ In other words the increased competition drives the lower part of the fare distribution down, letting the upper part almost unchanged. As a consequence, price dispersion increases as well as price discrimination.

This paper studies empirically the relationship between the price dispersion observed on the UK-Irish airline markets and their structure, in order to shed some light on which effect, monopoly or brand, predominates. We use a panel of 87,601 flight services operated between the UK and the Republic of Ireland during the period $1^{\text {st }}$ June 2003 and $31^{\text {st }}$ December 2004, for a total of 614,306 price observations. We find significant evidence that price dispersion increases with market power and, hence, that the monopoly effect prevails on the UK-Irish airline market.

Most of the empirical contributions on price dispersion in the Civil Aviation industry have focused, so far, mainly on the U.S. market (Borenstein, 1989; Borenstein and Rose, 1994; Hayes and Ross, 1998; Stavins, 2001; Gerardi and Shapiro, 2009). This work contributes to the existing literature by using data on European markets, whose deregulation was fully completed in 1997. Its ensuing effects were manifold, but the most noticeable has been the rapid growth of the Low Cost Carriers (LCCs): not only they opened up new routes and new destinations, but their low prices greatly extended demand, forcing the traditional, Full Service Carriers

\footnotetext{
${ }^{5}$ This explanation draws from Gerardi and Shapiro (2009).

${ }^{6}$ See Borenstein (1985), Holmes (1989) and Gale (1993).
} 
(FSCs) to respond by adapting their own operations and prices to compete more effectively. The strengthening of the LCCs position is revealed, for instance, by the fact that between June 2003 and December 2004 they operated almost $60 \%$ of the flights between the United Kingdom and Ireland.$^{7}$ In the paper we study possible pricing differences between these two types of carriers.

Furthermore, the focus on the UK-Irish markets allows us to add further insights on the possible effects of the proposed takeover of Aer Lingus by Ryanair, both Irish carriers, which the European Union Competition Commission decided to block arguing that the proposed acquisition would increase the market concentration and raise serious anti-competitive concerns (European Commission, 2007). Because our estimates indicate the predominance of the monopoly effect, the acquisition of a competitor might have therefore facilitated the exercise of price discrimination and harmed specific consumer segments. Implicitly, our analysis thus provides support to the EU Competition Commission's decision to block the merger.

The rest of the paper is structured as follows. The next section revises the literature, section II describes the econometric model, section III presents the results, section IV is devoted to the robustness checks, section V summarizes and concludes.

\section{Literature review}

In the context of introducing new products on the market, Stokey (1979) studies whether intertemporal price discrimination between early and late adopters can maximize the firm's profits. Under a continuum of consumers in continuous time and with the same discount rate for the firm and the consumers, she finds that the profit-maximizing strategy of the firm is to charge the same price in every period. This result, however, hinges on some assumptions, which, if relaxed, can sustain intertemporal price discrimination. For instance if we allow consumers' time preferences to differ and also to affect their reservation prices, then intertemporal price discrimination becomes a profitable strategy for the monopolist firm. ${ }^{8}$

Employing a model of advance purchases, Gale (1993) shows that the intensity of price discrimination in a non-cooperative duopoly is higher than in a monopoly, because the tougher competition among airlines for the less-time sensitive consumers reduces the lower tail of the price distribution and thus generates more price dispersion. This finding is in line with the previous works by Borenstein (1985) and Holmes (1989), who argue that price discrimination may be sustainable in oligopoly when products are differentiated and consumers have brand preferences. In particular, if

\footnotetext{
${ }^{7}$ Based on our own calculations based on data provided by the UK Civil Aviation Authority

${ }^{8}$ There are also other ways in which intertemporal price discrimination can turn out to be optimal, for example by allowing increasing marginal costs (assumed constant in the model) or by lessening the credible pre-commitment of the firm to charge a uniform price every period. For further examples see Varian (1989).
} 
the consumers' cross-elasticity between brands is lower than the industry elasticity, then there is some margin for the firm to segment consumers on their willingness to pay for the brand and, hence, to implement price discrimination successfully. Under this condition, neither increased competition nor lack of entry barriers can prevent airlines from engaging in price discriminatory strategies. ${ }^{9}$

Gale and Holmes (1993) show that if consumers have specified time of departure preferences, which characterize the flight to be peak and off-peak, then the firm can use advance purchase discounts to divert some of the demand from the peak to the off-peak period. This strategy is shown to expand the output and be superior to uniform pricing in maximizing the profit. An important corollary is that because the availability of discounted seats on the peak flights is very limited, off-peak flights should show more price dispersion than peak flights. In a similar fashion, but imposing ex ante uncertainty on which flight hits the peak of demand, Gale and Holmes (1992) show that advance purchase discounts are to be implemented in both types of flight (peak and off-peak) to smooth the demand peaks and reach allocative efficiency. Under relatively similar assumptions, Dana (1999a) shows that price dispersion arises because of stochastic demand and price rigidities, even when the peak of demand is unknown. In his view price dispersion results from the yield management techniques of the firm aiming to efficiently smooth the peaks of demand.

Under demand uncertainty and high inventory holding costs, Dana (1998) demonstrates that advance purchase discounts represent a plausible profit-maximizing strategy, even in the absence of market power. Thus firms tend to price discriminate consumers on the bases of their different extent of demand uncertainty rather than on their mere willingness to pay: by practicing advance purchase discounts firms are able to attract consumers with more certain demand first in order to reduce the costs associated to the risk of holding unutilized capacity.

Dana (1999b) uses a model with capacity constraints and aggregate demand uncertainty to explain price dispersion. Comparing the outcome of monopoly with the outcome of perfect competition, he finds that prices become more dispersed as markets become more competitive.

To sum up, the above theoretical works show that price dispersion induced by price discriminatory strategies represents the firms' best response to the demand conditions and industry's cost structure. Most importantly, price dispersion is not necessarily associated with higher market power, as instead argued by standard industrial economic theory. ${ }^{10}$ Indeed, the main results in Dana (1999b) point in the opposite direction: price dispersion is expected to increase as markets become more competitive.

Such a hypothesis is tested empirically in Borenstein and Rose (1994), where

\footnotetext{
${ }^{9}$ See Stole (2007) for further explanations.

${ }^{10}$ See Tirole (1988) for example.
} 
price dispersion is measured by the Gini coefficient calculated for each airline-route pair using a ten percent random sample of all tickets originating in the USA during the second quarter of 1986. The main findings from a set of regressions of the logarithm of the Gini coefficient on market structure variables, namely market share and Herfindhal index, reveal a negative and statistically significant effect of market concentration on price dispersion. However, in a study using three alternative measures of price dispersion (the Gini coefficient, the Atkinson index and the Entropy index), Hayes and Ross (1998) do not find a clear connection between market structure and price dispersion. This result may be driven by the change in consumers' elasticity between the 1980s, which include the sample period of Borenstein and Rose (1994), to the 1990s, which refer to the sample period by Hayes and Ross (1998), and by the consequent different pricing policies of airlines. Using a similar data set to Borenstein and Rose (1994), but working with fare as the dependent variable in level, Borenstein (1989) regresses the 20th, 50th and 80th percentile fare on market structure variable and on other independent variables meant to control for cost and quality factors. He finds a positive effect of market concentration on fare for the 20th and 50th percentile regressions while a negative effect for the 80th percentile. Since an increase in competition appears to reduce the lower part of the fare distribution to a larger extent than the higher part, the result by Borenstein (1989) may be considered an empirical case in favor of the brand effect mentioned earlier.

Stavins (2001) tests if price discrimination increases with competition on a cross sectional sample of tickets of different US carriers for flights operated on the same day and on different domestic routes. She controls for market structure, flight characteristics, demand features and approximates price discrimination with ticket restrictions such as Saturday-night stay over and advance-purchase requirement. She finds that price discrimination and price dispersion decrease with market concentration.

More recently, Gerardi and Shapiro (2009) extend the work of Borenstein and Rose (1994) using panel data from 1993 to 2006. Opposite to Borenstein and Rose (1994), they find a negative effect of competition on fare dispersion. Furthermore, this effect is mostly significant on routes characterized by passengers with heterogenous elasticity of demand, while on routes characterized by more homogenous passengers this effect becomes largely insignificant. Their results, therefore, constitute empirical evidence in favor of the monopoly effect. 


\section{$3 \quad$ Econometric model}

Our econometric approach hinges around the following reduced form model:

$$
\begin{aligned}
\text { IPD }_{\mathrm{it}}= & \mu_{1} \text { RMS }_{\mathrm{it}}+\mu_{2} \text { Flight }_{\mathrm{it}}+\theta_{1} \text { Frequency }_{\mathrm{it}}+ \\
& +\theta_{2} \text { Departime }_{\mathrm{it}}+\theta_{3} \text { ArriveDepart }_{\mathrm{i}}+\theta_{4} \mathrm{Xmas}_{\mathrm{it}} \\
& +\theta_{5} \text { Easter }_{\mathrm{it}}++\delta_{1} \text { Company }_{\mathrm{i}}+\delta_{2} \text { Route }_{\mathrm{i}}+\delta_{3} \text { Month }_{\mathrm{t}}+\rho_{i}+\varepsilon_{i t}
\end{aligned}
$$

where we control for market structure ( $\mu$ parameters), flight characteristics ( $\theta$ parameters), company characteristics, route characteristics and seasonality ( $\delta$ parameters). The appendix provides a detailed description on the sources of the data. Time $t$ is set weekly, $i$ represents a given flight code on a given route.

- $\underline{\text { RMS }}$ stands for Route Market Share, or simply market share, calculated by the ratio of the monthly number of flights operated by a given airline in a given route over the total monthly number of flights across all airlines in a given route. ${ }^{11}$ A positive sign on RMS supports the monopoly effect, whilst a negative sign is evidence of the brand effect. Because the majority of routes in the sample are either a monopoly or a duopoly, this variable is highly correlated with the Herfindhal index, which is therefore excluded from the model;

- Flights corresponds to the total number of flights across all companies operated in a given route and in a given month.

- Frequency represents the monthly frequency of a given flight code, as flight services can be offered daily or with less frequency, typically three times or twice a week.

- Departime controls for the departure time of the flight. Departime is charac-


h 6-10), Midday (h 10-14), Afternoon (h 14-18) and Evening (h 18-24). ${ }^{12}$

- ArriveDepart is a dummy variable equal to one if the flight originates in the $\overline{\mathrm{UK}}$ and equal to zero if it originates in the Republic of Ireland.

- $\underline{\mathrm{Xmas}}$ and Easter are two dummy variables equal to one during the weeks of Xmas/New Year and Easter respectively and equal to zero otherwise. They identify periods of peak demands on travel dates that have no alternative.

\footnotetext{
${ }^{11}$ Employing the number of flights instead of the number of passengers reduces possible endogeneity problems, because the number of flights is set well before the demand is realized, generally in the previous season. The airline's decision on this variable may still be correlated with a route fixed effects, an issue that we tackle using a panel fixed effects estimator.

${ }^{12}$ Note that no flights are allowed between midnight and $6 \mathrm{am}$.
} 
These dummies should be therefore associated with less intertemporal price dispersion because the airlines, during such periods, can condition their pricing strategies on the high willingness to pay of a more homogenous customer base.

- Company represents the set of company dummies, one for each airline of our sample: Aer Lingus, Bmibaby, British Airways, MyTravelLite and Ryanair as the omitted category.

- Month represents a set of monthly dummies capturing possible seasonality effects.

- $\rho$ is the flight code by route fixed effect, assumed time invariant within each flight code. ${ }^{13}$

- $\varepsilon$ is the standard regression error, assumed to be random with zero mean.

The dependent variable IPD is alternatively represented by three different measures of inequality: the Gini coefficient, the Atkinson index and the Entropy index. ${ }^{14}$ There are a number of advantages in using such indexes. First, they have the desirable property of being scale invariant (i.e. multiplying all fares by a positive constant does not change the value of the measure), which allows us to compare distributions of different magnitudes. Second, because their calculation entails the entire distribution of available fares, they are preferable to such indexes as the lowest to highest ratio or the range, which only use two observations out of the entire sample, and are therefore sensible to outliers. Furthermore, it may be possible that different distribution of fares may have the same value of, e.g., the range index. Finally, since these three indexes are already employed in previous empirical studies on airline price dispersion, they allow for result comparability with the existing literature (see, e.g., Borenstein and Rose, 1994; Hayes and Ross, 1998; Gerardi and Shapiro, 2009).

\footnotetext{
${ }^{13}$ Because each flight code is company specific by definition, the company fixed effect is already absorbed into $\rho$.

${ }^{14}$ In formulae:

Gini $=1+\frac{1}{N}-\frac{2}{\lambda N^{2}} \Sigma_{i=1}^{N}(N+1-i) p_{i}$

Atkinson $= \begin{cases}1-\frac{1}{\lambda}\left(\frac{1}{N} \sum_{i=1}^{N} p_{i}^{1-\phi}\right)^{1 /(1-\phi)} & \text { for } \forall \phi>0 \text { and } \phi \neq 1 \\ 1-\frac{1}{\lambda}\left(\prod_{i=1}^{N} p_{i}\right)^{1 / N} & \text { for } \phi=1\end{cases}$

Entropy $= \begin{cases}\frac{1}{N} \sum_{i=1}^{N}\left[\left(\frac{p_{i}}{\bar{\lambda}}\right)^{\phi}-1\right] & \text { for } \forall \phi \neq 0 \text { and } \phi \neq 1 \\ \frac{1}{N} \sum_{i=1}^{N}\left(\frac{p_{i}}{\bar{\lambda}}\right)^{\phi} \cdot \ln \frac{p_{i}}{\bar{\lambda}} & \text { for } \phi=0 \text { or } \phi=1\end{cases}$

where $p_{i}$ is the price of observation $i$, with $i=1,2, \ldots, N ; \lambda$ is the mean price and $\phi$ is the choice parameter. For a detailed description of these indexes see Jenkins (1991) or Cowell (1995).
} 
Each index places different weights to different part of the distribution. The Gini coefficient gives more weight to the central part of the distribution while it remains quite unaffected by the tails. The Atkinson index, on the contrary, is more sensitive to the upper end of the distribution. This index is calculated under three alternative choice parameters $\phi: 0.5,1$ and 2 ; higher parameters amplify the effect of the upper tail, whilst lower parameters smooth it. Finally, the Entropy index places more weight on the lower part of the distribution and is calculated under three different alternative parameters $\phi: 0,1$ and 2; the lower the parameter, the stronger the emphasis on the fare variation at the bottom of the distribution. Their joint evaluation therefore provides a general and robust indication on the reliability of the results. Most importantly, the use of different values of $\phi$ allows an indirect evaluation of the prevalence of the effects under study: "monopoly" vs. "brand". If the former prevails, as $\phi$ increases we should then expect an increase in the coefficient of the market share variable when we use the Atkinson index, and a decrease for the Entropy index case. Viceversa if it is the latter effect to drive the airlines' pricing.

We calculate the Gini, the Atkinson and the Entropy for each week and for each flight code using a series of different fares posted on the internet $7,10,14,21,28$, 35, 42, 49 and 56 days before the departure. Table 1 reports the summary statistics. Overall, i.e. across all companies and all routes of our sample, the average Gini is approximately 0.35 , which implies that the expected difference in fares between two random passengers on a given flight is on average 70 percent of the airline's average ticket fare. ${ }^{15}$ This result is higher than what found with US data (36 percent in Borenstein and Rose (1994), 44 percent in Gerardi and Shapiro (2009)), which may depend on the large presence of LCCs, which traditionally show greater fare dispersion.

Table 2 provides a breakdown of the Gini coefficient by airline. We observe that the three LCCs of our sample are associated with the three highest averages of the Gini coefficient, while the two FSCs exhibit the two lowest.

\section{Results}

Equation (1) is estimated using both Pooled Ordinary Least Squares (OLS) and Panel Fixed Effects (FE). The Gini coefficient and the Atkinson index, which range between zero and one by construction, are unbound with the usual log odds ratio transformation. ${ }^{16}$ The standard errors are clustered by route and week to control for possible residuals' correlation between flights of different companies serving the

\footnotetext{
${ }^{15}$ The expected absolute fare difference as a proportion of the mean fare for two passengers randomly drawn is equal to twice the Gini coefficient.

${ }^{16}$ I.e. the $\log$ odds ratio of $y$ is equal to $\log y /(1-y)$.
} 
same route and departing during the same week. ${ }^{17}$

Table 3 reports the estimates of equation (1) when IPD is represented by the $\log$ odds ratio of the Gini and the log odds ratio of the Atkinson under its three specifications. Table 4 completes table 3 by reporting the coefficients of equation (1) when the Entropy index under its three specifications is the dependent variable.

From both Tables we observe a clear pattern indicating a positive and often statistically significant impact of market share on fare dispersion. Using the FE estimates to quantify the effect of market share on price dispersion, we obtain that an increase of RMS by one-standard-deviation raises the Gini coefficient by 0.02 , the Atkinson index between 0.02 and 0.09, the Entropy index between 0.08 and $0.16 .^{18}$

The positive sign, which is found across all 14 specifications, thus appears to lend strong support in favor of the monopoly effect. ${ }^{19}$ That is, IPD intensifies in more concentrated markets, possibly because concentration facilitates the extraction of consumer surplus from last-minute passengers with an inflexible travel schedule. Given the structure of the UK-Irish airline market, which is characterized by several duopoly as well as monopoly routes, this effect is somehow to be expected: few companies with a large market share on a route can easily price discriminate with little concern about their competitors' pricing strategies. Moreover because LCCs, which are largely present in our sample, do not implement frequent flyer programs, consumers have little incentives to remain loyal to an airline and hence there are weak premises to sustain the brand effect. ${ }^{20}$

This argument is corroborated by the magnitude of the coefficients of market share across all our indexes of IPD. Recall that the Gini coefficient gives more emphasis to the middle part of the distribution, the Atkinson index to the upper part and the Entropy index to the lower part. Recall also that a higher choice parameter in the Atkinson index and in the Entropy index tends to amplify the effect of

\footnotetext{
${ }^{17}$ Think, for instance, of temporary shock such as a football match or a music festival: during the week of the event airline fares are likely to peak irrespectively of the company and of the booking period, resulting in lower fare dispersion.

${ }^{18}$ For the Gini and Atkinson models, we calculate the marginal effect of RMS on the dependent variable evaluated at the sample mean. Formally the marginal effect stems from the following procedure. First, express equation (1) only with respect to the variable of interest, $\log \left(\frac{y}{1-y}\right)=\mu \mathrm{RMS}$, where $y$ is either the Gini coefficient or the Atkinson index. Totally differentiating yields: $\partial y / \partial R M S$ $=\mu y(1-y)$. Second, choose the sample mean of $y$ (see table 1 ), at which to evaluate $\partial y / \partial \mathrm{RMS}$ and consider 0.254 as one-standard-deviation of RMS. For the Entropy models, estimating the marginal effect is slightly simpler as the dependent variable is expressed in levels; that is the model is in the form $y=\mu \mathrm{RMS}$, and therefore $\partial y / \partial \mathrm{RMS}=\mu$.

${ }^{19}$ With respect to the existing empirical literature, this result confirms, using a European sample of both LCCs and FSCs, the findings by Gerardi and Shapiro (2009) obtained from a US sample of only FSCs.

${ }^{20}$ The brand effect is sustainable if the firm is able to discriminate customers with respect to their brand preferences (Borenstein, 1985) and, hence, frequent flyer programs represent a typical tool to make passengers loyal to the brand.
} 
price variation respectively at the upper and at the lower tail of the distribution. If the monopoly effect occurs, the price variation of the upper part of the distribution (price inelastic consumers) should be larger than the price variation of the lower part of the distribution (price elastic consumers). Therefore, if the monopoly effect occurs, as we increase the choice parameter of the dispersion index, we should observe a mounting effect of market share on IPD under the Atkinson index specification, whilst a lowering effect under the Entropy index specification. Focusing our discussion on the fixed effect estimates of tables 3 and 4 , we precisely observe this pattern, with only one minor exception as we shift from model Entropy(1) to model Entropy(2); nonetheless, the estimated coefficient on market share under model Entropy $(2)$ is half the coefficient estimated under model Entropy(0).

A further test of the notion that IPD is generally motivated by passengers' heterogeneity is provided by the analysis of the dummies identifying two peak periods. Across all specifications the coefficients on the two holiday dummies, Xmas and Easter, are negative and highly statistically significant, suggesting that for flights departing during the Christmas or Easter period fares are less dispersed than the average. During such periods, the airline appear to charge a high fare throughout the 52 days before departure. That is, the gap between the max and the min fares shrinks during those holiday periods, implying a less dispersed fare distribution than in "normal" periods. We call this airlines' practice "inter-period" price discrimination, as different types of passengers are identified according to their chosen traveling period. Moreover, the higher absolute magnitude in most of the cases ${ }^{21}$ of the Xmas coefficient over the Easter coefficient proves that the inter-period effect is stronger during Christmas than during Easter. This result most likely reflects an obvious presumption on travelers' ranking of holiday preferences. That is, most Irish people living in Britain and Britons living in Ireland would consider Christmas as the most important occasion to reunite with friends and family.

The positive and statistically significant sign on Frequency indicates that flight services operated daily are more price dispersed than flight services operated with less frequency. Interestingly a steeper fare distribution on daily flights can be explained by a rise either in the high tail of the daily flights or in the low tail of less frequent flights. The former case occurs if we assume that more flight frequency improves the convenience of traveling on the route and that price inelastic consumers are willing to pay an extra for such increased product quality. ${ }^{22}$ The latter case occurs when, due to lower supply, price elastic bookers of less frequent flights have few flight alternatives and thus accept a higher fare. ${ }^{23}$ However, given the two dec-

\footnotetext{
${ }^{21}$ The two cases out of 14 in which the order is reversed correspond to the only two cases in which Xmas is statistically insignificant.

${ }^{22}$ This case is in line with Borenstein and Rose (1994, page 660) who argue that "under monopolytype discrimination, improvements in the service would then imply increased price discrimination."

${ }^{23}$ Recall that the price elastic bookers are those who shop around, across different departure
} 
imal digits of the coefficient, the effect of Frequency on IPD in magnitude terms is relatively small.

The positive and statistically significant coefficient on Flights indicates that routes served by a larger amount of flights show more price dispersion. Although a similar argument to Frequency may apply, the magnitude of the coefficient on Flights is so small across all the specifications that its actual impact on IPD becomes negligible.

With Ryanair as the omitted airline, the negative coefficient on all the remaining company dummies in the Pooled model indicates that Ryanair has on average the highest degree of fare dispersion in our sample, as initially indicated in Table 2. The route dummies, not reported to save space but included in the Pooled model, show also a stable and interesting pattern. Setting Stansted-Dublin as the omitted category, all the remaining route dummies are positive and statistically significant except Heathrow-Dublin, which is negative and statistically significant. This result indicates that in markets which are smaller than the London-Dublin one, competitive forces are probably weaker and airlines fully implement IPD, especially by lifting the upper part of the fare distribution to take advantage of price inelastic consumers. On the contrary, in the London-Dublin market each consumer group faces a variety of imperfect substitutes, which constrains the airlines' ability to engage in price discrimination. Henceforth, this will be referred to as the "London-Dublin effect".

From the variables controlling for the time of departure we deduce that flights scheduled to depart in the evening have the least dispersed fare distribution. Given that our sample is composed by very short haul routes with an average journey of about an hour, it generally appears more convenient for consumers to fly in the evening, as they can travel off office hours and/or use more efficiently their time during the day. Such improvement in the quality of the product is acknowledged by a rise in the passengers' reservation price. Therefore, since the demand of evening flights is composed by a smaller amount price elastic consumers, the airline can increase the lower bound of the fare distribution and still make sales. All else being equal, an upper lift of the lower bound of the distribution means less dispersion. ${ }^{24}$ We will refer to this case as the "evening-effect".

\section{Robustness}

The investigation of the previous section has found empirical evidence in favor of a positive and significance effect of competitive forces on price dispersion. In this

days in order to obtain the lowest fare. If a flight code is operated with less frequency, then they have less options to choose and hence they cannot be too rigid on their reservation price.

${ }^{24}$ As argued by Borenstein and Rose (1994), evening flights could also be associated with airport congested periods and thus with more expensive slots. More costly flights are normally allocated fewer discount tickets, resulting in a higher average fare and a flatter fare distribution. 
section we provide additional evidence to support this result: we control for the possible endogeneity bias using instrumental variables; we re-estimate the model under a broader definition of route, the city pair; we employ different alternative functional forms; we replicate the model on another data set of airline fares. To save space, and to account for possible correlation between our regressors and the fixed effect $\rho_{i}$, in the remainder of the paper we report only the Panel Fixed Effects (FE) coefficients (the Pooled estimates are available on request).

\subsection{Instrumental Variables}

However, it is possible that RMS may be correlated with the $\epsilon_{i t}$, so that the potential endogeneity may bias the results previously presented. Therefore, we re-estimate equation (1) with Instrumental Variables (IVs), using the IV in Borenstein (1989) and Borenstein and Rose (1994) (henceforth, B\&R).

Table 5 reports the fixed effect estimates using the IV of $\mathrm{B} \& \mathrm{R}$, corresponding to the ratio between the observed carrier's geometric mean of the enplanement (i.e. the number of passengers boarding the aircraft) at the endpoints of the route and the sum across all carriers of the geometric mean of each carrier's enplanement at the endpoints. ${ }^{25}$

The IV analysis confirms all the main empirical results and implications of the previous section. Indeed, market share stays positive across all specifications and statistically significant five times out of seven. Tables 5 also shows results consistent with previous findings. The holiday dummies, Xmas and Easter, remain negative and practically always highly statistically significant, confirming that during the peak of the holiday season IPD is lower. This result confirms that airlines appear to practice some forms of inter-period price discrimination to channel price elastic passengers to the off-peak period and screen the price inelastic consumers into the peak period where airline can extract higher surplus. Frequency and Flights remains positive, statistically significant and with the usual low effect in magnitude terms. The evening-effect, i.e., lower price dispersion for evening flights, seems to fade under the IV estimation: the sign of the coefficient is still negative 12 times out of 14 , but statistically significant only five times. Given that the time table of each flight service has normally minor changes during the year (usually associated with the change of the season) and given that the FE bases its estimation on the deviation

${ }^{25}$ In formula:

$$
G E N P S H=\frac{\sqrt{E N P_{x 1} * E N P_{x 2}}}{\sum_{y} \sqrt{E N P_{y 1} * E N P_{y 2}}}
$$

where $x$ indexes the observed airline, $y$ indexes all the airlines, $\operatorname{ENP}_{y 1}$ and $\operatorname{ENP}_{y 2}$ are airline $y$ 's monthly enplanement at endpoint 1 and at endpoint 2, respectively. The higher the airport dominance (measured by GENPSH) of a given airline, the higher the likelihood that the observed airline dominates (i.e. it has a high market share on) the observed route. 
from the within group mean, the estimates of variables characterized by very little time-variation, such as Evening, are not entirely reliable. Furthermore, the Pooled estimate of Evening, not reported in table 5, is negative and statistically significant across all specifications and thus provides yet some support in favor of the eveningeffect. The route dummies of the Pooled estimation are also in line with the results of table 3 and corroborate the London-Dublin effect. Finally the company dummies of the Pooled estimation are also unchanged and thus indicate that in our sample Ryanair is on average the carrier with the highest price dispersion, while British Airways the carrier with the lowest.

\subsection{City pair}

Since flights to different airports in the same metropolitan area could be considered imperfect substitutes and thus compete with one another, equation (1) is reestimated under the city pair definition. Formally a city pair includes all the airports serving a given metropolitan area and defines the relevant market as the combination of all airport pairs available between two cities. ${ }^{26}$

Because under city pair the number of markets reduces, when assessing the magnitude of the effect of market share on IPD it is advisable to consider, in addition to the usual regression estimates, the standardized beta coefficients, which are obtained from a regression of IPD where all the variables including the market share, taken separately for the city pair and the route dimension, are normalized with mean zero and variance equal to 1 . To facilitate comparability of results under the two possible measures of market share, table 6 , as well as reporting the estimates using the actual values of all regressors, includes in square brackets the estimated beta coefficients relative both to the city pair and the route normalized variables.

Consistent with previous results, the coefficient on market share is positive and highly significant across all specifications; furthermore, the beta coefficient under the city pair dimension is consistently higher than the corresponding beta coefficient under the route dimension. Such a result indicates that the effect of competition on price dispersion is stronger in magnitude when we take the city pair instead of the route as the relevant market. This is most likely due to the different possible market configurations that may characterize a route and a city pair. Consider the following three types of routes: (i) routes that show some extent of competition among firms, defined as "competitive-route", (ii) routes that are close to a monopoly

\footnotetext{
${ }^{26}$ We identify six city pairs for the UK, while none for the Republic of Ireland. The airports associated to each city pair are in parentheses: East Midlands (Birmingham and Nottingham), London (City, Gatwick, Heathrow, Luton and Stansted), North East (Newcastle and Teesside), North West (Blackpool, Liverpool and Manchester), Scotland (Edinburgh and Glasgow) and Wales (Bristol and Cardiff). Therefore, for example, the city pair London - Dublin includes all the airports in the London area (City, Gatwick, Heathrow, Luton and Stansted) and the only airport in the Dublin area (Dublin Airport).
} 
under the route dimension, but that turn into competitive-routes under the city pair dimension and are referred to as "weak-monopoly", (iii) routes that are close to a monopoly under the route dimension and that remain as such also under the city pair dimension, which we define "strong-monopoly". Thus, a high market share under the city pair specification implies a genuinely dominant position of the airline on the market which is then tantamount to the strong-monopoly case. In such a market the firm does not suffer from the competition of other flights operated by other airlines on the same city pair and pricing is driven by the monopoly effect. Interestingly, we observe a larger effect in the magnitude of the city pair market share on IPD relative to the case of the route market share, which is a consequence of the fact that airlines adjust their fares more freely when they enjoy a higher degree of market power.

Finally, we note that the sign and significance of the other regressors remain very similar to the results of the IV analysis.

\subsection{Functional Forms}

We also explore whether different functional forms may affect our results by running the following alternative specifications of equation (1):

1. Use the natural logarithm of market share in place of RMS.

2. Include the market share of the nearest competitor.

3. Include one dummy for monopoly routes and one dummy for duopoly routes, as in Borenstein and Rose (1994). ${ }^{27}$

Log of market share - Table 7: the positive coefficient on the logarithm of market share across all specifications confirms the positive impact of market share on IPD. ${ }^{28}$

Competitor's market share - Table 8: as expected, when we include the market share of the nearest competitor, the sign is positive for RMS and negative for the nearest competitor's market share; a larger market share of the competitor erodes the observed carrier's market power and constrains its ability to adopt pricing strategies that increase dispersion. Although the inevitable correlation between the observe carrier's market share and the nearest competitor's market share may affect the significance of RMS, the estimates of table 8 confirm the positive relationship between firm's market power and price dispersion.

\footnotetext{
${ }^{27}$ Monopoly is defined as a route in which a single airline has a market share of at least $90 \%$. Duopoly is a non-Monopoly route in which two airlines have a joint market share of at least $90 \%$.

${ }^{28}$ We have run a regression including a linear and a quadratic term for RMS: although we get qualitatively similar results, these estimates are not reported given the high collinearity between RMS and $\mathrm{RMS}^{2}$. These estimates are available on request.
} 
Monopoly and Duopoly dummies - Table 9: As previously stated, the features of the UK-Irish airline market, which is characterized by the presence of few companies on each route, make it difficult to include in the model more than one variable to control for the different aspects of market structure. Therefore, we omit the market share variable and replace it with two measures of market concentration, Monopoly and Duopoly. The positive and sometimes significant sign for the former and the generally negative and significant one for the latter further support the prevalence of the monopoly effect. Moreover, the Duopoly coefficient in the Atkinson index regressions increases in magnitude but loses significance as the index gives more weight to the upper end of the fares distribution, i.e., as $\phi$ increases. The opposite occurs in the Entropy index regression: both results suggest that the dispersion of fares is smaller in Duopoly markets.

\subsection{International Passenger Survey}

To assess the reliability of our results obtained using on-line fares, we re-estimate our model using a new sample of fares from actual transactions. This new data set is taken from the International Passenger Survey (IPS), ${ }^{29}$ which is a survey of a random sample of passengers entering/leaving the UK by air. The questionnaire data provide useful information on the expenditure levels of inbound and outbound tourists and includes, in addition to the route and the carriers' name, the fare paid by each interviewed passenger. Similar to the U.S. Department of Transportation's Origin and Destinations database, the IPS survey does not indicate the date the ticket was purchased; however, considering that the survey consists of a random draw of passengers, we can reasonably assume that IPS fares are randomly distributed across the booking periods and that therefore IPS fares to a great extent replicate the booking pattern of our online fares.

Equation (1) is therefore re-estimated using the IPS fares pertaining to all the UK-Ireland routes for the same sample period of the previous analysis, namely from June 2003 to December 2004. Due to lack of information, $i$, the panel identifier, is now represented by the pair airline-route and $t$, the time frame, is set monthly. ${ }^{30}$ As a consequence, the new equation to be estimated is a slightly modified version of equation (1), because we do not define the time of the flight departure and the holiday dummies. Furthermore, the variable "Frequency" now comprises the total number of flights operated by a given airline in a given month on a given route.

\footnotetext{
${ }^{29}$ The data set is provided by UK Office for National Statistics and distributed by the UK Data Archive.

${ }^{30}$ The IPS provides also the flight code associated with each passenger and therefore potentially equation (1) could be estimated using the flight code as panel identifier. In practice, however, the number of fare observations for each combination flight code-month is on average so small that the dispersion index often cannot be computed. Therefore considering the pair airline-route as the unit of observation represents the best available approximation.
} 
Overall, given the different unit of observation, the model specification with the IPS data allows a reliable comparison with the results previously obtained, especially considering that the variable of interest, Route Market Share, is taken from the same source, the UK Civil Aviation Authority. Note also that with respect to our original sample, this new estimation comprises additional routes and airlines. ${ }^{31}$

Table 10 reports the results: the statistically significant positive sign on Route Market Share across all the seven specifications is in line with previous results. Given the wider set of routes taken into consideration, finding a positive effect of market share on price dispersion when the dependent variable is obtained from survey data corroborates the general conclusion from our analysis that the monopoly effect appears to be prevalent in the UK-Irish airline market.

\section{Conclusion}

In this paper we have studied how competitive forces affect the intertemporal price dispersion of airline fares. Using different fares posted online at different days before the departure for 87,601 flights operated between the UK and the Republic of Ireland during the period $1^{\text {st }}$ June 2003 and $31^{\text {st }}$ December 2004, we have calculated several indexes of dispersion and tested whether airlines' market share has a positive or a negative effect on such price dispersion.

We have found that market share has a positive and statistically significant impact on intertemporal price dispersion and, hence, we provide empirical evidence in favor of the monopoly effect. We have estimated that for a one-standard-deviation increase of market share, price dispersion would raise between 0.02 and 0.16 , depending on the measure of dispersion considered. This result occurs because a higher market share allows the airline to separate price inelastic passengers, who are mostly late bookers, from price elastic passengers, who are typically early bookers, and accordingly charge a higher price to the former group.

In high-demand periods, when the airline can focus their pricing strategies on a specific group of passengers with high willingness to pay, we have also found that fares of flights departing during the weeks of Christmas and Easter are on average less dispersed. This result is consistent with an inter-period price discriminatory strategy, where the lower bound of the fare distribution during the peak period is raised, leading to an overall reduction in fare dispersion.

The conclusions of our econometric analysis are robust to different specifications, to several functional forms, to the use of instrumental variables; furthermore, the

\footnotetext{
${ }^{31}$ In addition to the airlines in table 2, the IPS survey includes passengers flying with Arann Express, British European and Cityjet. Additional routes not in our previous analysis are: Birmingham-Cork, Birmingham-Knock, Birmingham-Shannon, East Midlands-Knock, GatwickCork, Heathrow-Shannon, Luton-Dublin, Luton-Galway, Manchester-Galway and ManchesterKnock.
} 
conclusions do not change when we calculate the indexes of fare dispersion using the fares paid by passengers participating to the UK International Passenger Survey.

Because of its focus on the UK-Irish market, the analysis also sheds further light on the possible consequences of the attempted takeover of Aer Lingus by Ryanair, which was blocked because the acquisition would have significantly impeded effective competition by creating a dominant position of the combined entity on 35 routes from and to Dublin, Shannon and Cork, and the creation or strengthening of a dominant position on 15 other routes from and to Dublin and Cork. (European Commission, 2007, p. 345). Particularly important to our analysis is the fact that out of the 35 intra-European routes operated by both parties, the acquisition would have led to monopoly in 22 routes, and to a dominant position with a joint market share of more than $60 \%$ on the remaining routes. ${ }^{32}$ Thus, the evidence in this paper generally lends support to the European Commission's decision, although the latter's investigation did not explicitly address the relationship between fare dispersion and market concentration. Indeed, because the monopoly effect appears to be associated with an increase in the fares in the upper end of the distribution, while fares in the lower end remain largely stable except in holiday periods, the takeover would have been particularly harmful to certain segments of consumers - in this particular case, those with uncertain demand whose need to book a flight is generally revealed just a few days prior to a flight's departure.

\footnotetext{
${ }^{32}$ The Commission's analysis considers also other European markets outside the British Isles.
} 


\section{References}

[1] Borenstein S. (1985) "Price Discrimination in Free-Entry Markets" RAND Journal of Economics, 16(3), pp. 380-397

[2] Borenstein, S. (1989) "Hubs and high fares: dominance and market power in the US airline industry" RAND Journal of Economics, 20(3), pp. 344-365

[3] Borenstein S., and N. Rose (1994) "Competition and Price Dispersion in the U.S. Airline Industry" Journal of Political Economy 102(4) pp. 653-683

[4] Cowell F. (1995) "Measuring Inequality" (second edition). Hemel Hempstead, England: Harvester Wheatsheaf.

[5] Dana J. (1998) "Advance-Purchase discounts and price discrimination in competitive markets," Journal of Political Economy, Vol. 106(2), pp. 395-422.

[6] Dana J. (1999a) "Using yield management to shift demand when the peak time is unknown," RAND Journal of Economics, Vol. 30(3), pp. 456-74.

[7] Dana J. (1999b) "Equilibrium price dispersion under demand uncertainty: the roles of costly capacity and market structure," RAND Journal of Economics, Vol. 30(4), pp. 632-60.

[8] European Commission (2007) Case No COMP/M.4439 Ryanair/Aer Lingus. http://ec.europa.eu/comm/competition/mergers/cases/decisions/m44392007062720610en.pdf

[9] Gale I. (1993) "Price Dispersion in a Market with Advance-Purchases" Review of Industrial Organization 8, pp. 451-464.

[10] Gale, I. and Holmes, T. (1992) "The efficiency of advance-purchase discounts in the presence of aggregate demand uncertainty" International Journal of Industrial Organization, Vol. 10, pp. 413-37.

[11] Gale, I. and Holmes, T. (1993) "Advance-Purchase discounts and monopoly allocation capacity" American Economic Review, Vol. 83(1), pp. 135-46.

[12] Gerardi K. and A. Shapiro (2009) "Does Competition Reduce Price Dispersion? New Evidence From the Airline Industry" Journal of Political Economy 117(1) pp. 1-37.

[13] Giaume, S. and S. Guillou (2004), "Price Discrimination and Concentration in European airline markets", Journal of Air Transport Management, 10, pp. 305-310. 
[14] Hayes K. and Ross L. (1998) "Is Airline Price Dispersion the Result of Careful Planning or Competitive Forces?" Review of Industrial Organization 13(5), pp. 523-541.

[15] Holmes T. (1989) "The Effects of Third-Degree Price Discrimination in Oligopoly," American Economic Review 79, pp. 244-250

[16] Jenkins S. (1991) "The measurement of income inequality", chapter 1 in L Osberg (ed) Economic Inequality and Poverty: International Perspectives, pp. 3-38. M E Sharpe, Armonk NY, 1991.

[17] Piga C. A., and E. Bachis. (2007). "Pricing strategies by European traditional and low cost airlines: or, when is it the best time to book on line?" in Lee, D. (ed.), Advances in Airline Economics. The Economics of Airline Institutions, Operations and Marketing. Vol. 2. Elsevier, ch. 10, 319-343.

[18] Stavins J. (2001) "Price discrimination in the airline market: The effect of market concentration" Review of Economics and Statistics, 83(1), pp. 200-202

[19] Stokey N. (1979) "Intertemporal Price Discrimination" Quarterly Journal of Economics, 93, pp. 355-371

[20] Stole L. 2007 "Price Discrimination and Competition" Handbook of Industrial Organization, Elsevier

[21] Tirole J. (1988) "The Theory of Industrial Organization" Cambridge, MA: The MIT Press

[22] Varian H. (1989) "Price Discrimination" in R. Schmalensee and R. Willig, eds., Handbook of Industrial Organization: Volume I, pp. 597-654, North-Holland, Amsterdam. 


\section{Appendix: Sources of Data}

This empirical investigation uses two main data sets, one containing primary data on posted fares, the other providing market structure measures derived from secondary data provided by the UK Civil Aviation Authority (CAA).

All the fares are obtained from the internet using a web spider, which accessed the web-sites of the LCCs included in the sample (Ryanair, Bmibaby and Mytravellite), and retrieved the fares of the FSCs, namely Aer Lingus and British Airways, from an on-line travel agent, Opodo. ${ }^{33}$ For each day between $1^{\text {st }}$ June 2003 and $31^{\text {st }}$ December 2004 and for each flight code, the spider collected all the posted fares that a hypothetical consumer would pay when buying the ticket $7,10,14,21,28$, $35,42,49$ and 56 days before the departure day.

LCCs price each leg independently and the retrieved fares refer to a single oneway ticket. FSCs, instead, reflect a more sophisticated yield management technique that usually makes it uneconomical for the consumers to buy each leg independently. ${ }^{34}$ Therefore, for the FSCs the spider collects round-trip fares, which could be considered more representative of the actual fare pattern observed by consumers. Furthermore, because the LCCs' fares do not include such restrictions as Saturdaynight stay over, the spider is programmed to have the return leg scheduled one week after the outgoing flight. To make a round trip fare comparable with a LCC oneway fare, we follow the traditional approach in the literature to halve the former (Borenstein, 1989; Borenstein and Rose, 1994). Before we do so, we deal with the fact that each first leg could be combined with different return flights, each differing by departure time. The spider retrieved all these possible combinations of fares, which we use to construct a daily average round-trip fare.

The UK Civil Aviation Authority provides census monthly data for the full set of flights operated between the UK and Ireland during the period June 2003 December 2004. This data set contains information on the frequency, the number of passengers and the available seat capacity of each flight code, which are used to construct various market structure variables.

\footnotetext{
${ }^{33}$ See www.opodo.co.uk, which is owned and managed by British Airways, Air France, Alitalia, Iberia, KLM, Lufthansa, Aer Lingus, Austrian Airlines, Finnair and the global distribution system Amadeus. Thus, fares listed on Opodo represent the official prices of each airline; although Opodo may not report promotional offers that an airline may post on its own website.

${ }^{34}$ FSCs normally price a round-trip ticket cheaper than two separate one-way tickets, so that consumers have the incentives to purchase round-trip tickets; the airline is thus able to implement second degree price discrimination (Giaume and Guillou, 2004).
} 
Table 1: Summary statistics of the measures of price dispersion

\begin{tabular}{lccccc}
\hline Dispersion measure & Mean & Std. Deviation & Observations & Min & Max \\
\hline \hline Gini & 0.347 & 0.165 & 14,435 & 0 & 0.875 \\
Atkinson(0.5) & 0.144 & 0.121 & 14,435 & 0 & 0.744 \\
Atkinson(1) & 0.313 & 0.252 & 14,435 & 0 & 0.993 \\
Atkinson(2) & 0.546 & 0.368 & 14,435 & 0 & 1.000 \\
Entropy(0) & 0.479 & 0.518 & 14,435 & 0 & 4.995 \\
Entropy(1) & 0.277 & 0.241 & 14,435 & 0 & 1.864 \\
Entropy(2) & 0.329 & 0.364 & 14,435 & 0 & 4.685 \\
\hline
\end{tabular}

Table 2: Summary statistics of the Gini coefficient across airlines

\begin{tabular}{lccccc}
\hline Airline & Mean & Std. Deviation & Observations & Min & Max \\
\hline \hline Aer Lingus & 0.190 & 0.089 & 3,273 & 0 & 0.513 \\
Bmibaby & 0.213 & 0.086 & 939 & 0 & 0.501 \\
British Airways & 0.098 & 0.044 & 290 & 0 & 0.182 \\
MyTravelLite & 0.353 & 0.120 & 337 & 0 & 0.695 \\
Ryanair & 0.421 & 0.141 & 9,596 & 0 & 0.875 \\
\hline
\end{tabular}




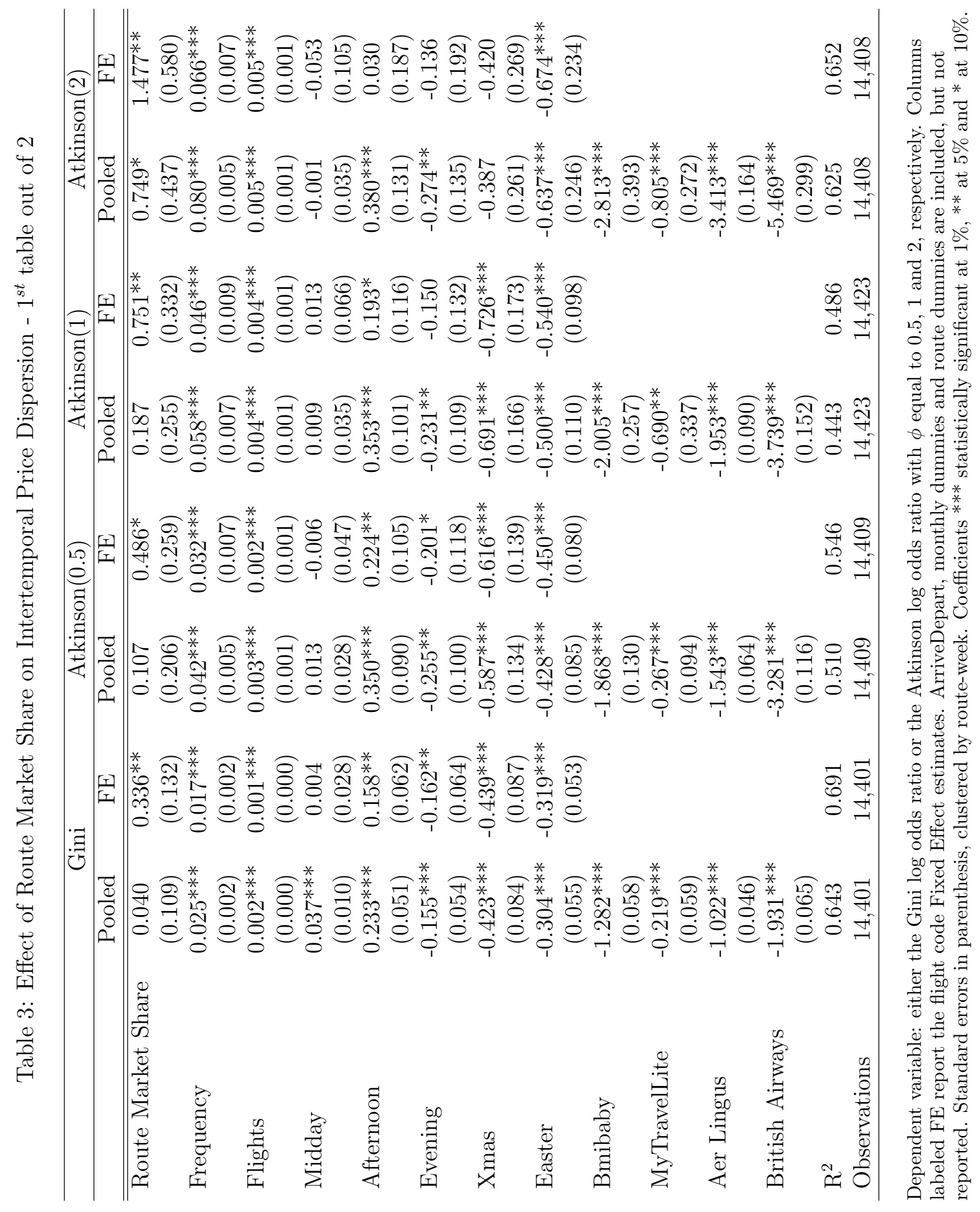


Table 4: Effect of Route Market Share on Intertemporal Price Dispersion - $2^{\text {nd }}$ table out of 2

\begin{tabular}{|c|c|c|c|c|c|c|}
\hline & \multicolumn{2}{|c|}{ Entropy $(0)$} & \multicolumn{2}{|c|}{ Entropy(1) } & \multicolumn{2}{|c|}{ Entropy $(2)$} \\
\hline & Pooled & $\mathrm{FE}$ & Pooled & $\mathrm{FE}$ & Pooled & $\mathrm{FE}$ \\
\hline "Route Market Share & $\begin{array}{c}0.261^{* * *} \\
(0.081)\end{array}$ & $\begin{array}{c}0.628^{* * *} \\
(0.105)\end{array}$ & $\begin{array}{l}0.059 * \\
(0.035)\end{array}$ & $\begin{array}{c}0.234^{* * *} \\
(0.041)\end{array}$ & $\begin{array}{c}0.029 \\
(0.053)\end{array}$ & $\begin{array}{c}0.321^{* * *} \\
(0.059)\end{array}$ \\
\hline Frequency & $\begin{array}{c}0.004^{* * *} \\
(0.001)\end{array}$ & $\begin{array}{c}0.003^{* * *} \\
(0.001)\end{array}$ & $\begin{array}{c}0.003^{* * *} \\
(0.000)\end{array}$ & $\begin{array}{c}0.001^{* * *} \\
(0.000)\end{array}$ & $\begin{array}{c}0.004^{* * *} \\
(0.001)\end{array}$ & $\begin{array}{c}0.002^{* * *} \\
(0.001)\end{array}$ \\
\hline Flights & $\begin{array}{c}0.002^{* * *} \\
(0.000)\end{array}$ & $\begin{array}{c}0.002^{* * *} \\
(0.000)\end{array}$ & $\begin{array}{c}0.001^{* * *} \\
(0.000)\end{array}$ & $\begin{array}{c}0.001^{* * *} \\
(0.000)\end{array}$ & $\begin{array}{c}0.001^{* * *} \\
(0.000)\end{array}$ & $\begin{array}{c}0.001^{* * *} \\
(0.000)\end{array}$ \\
\hline Midday & $\begin{array}{c}-0.025^{* * *} \\
(0.006)\end{array}$ & $\begin{array}{c}-0.041^{* *} \\
(0.018)\end{array}$ & $\begin{array}{l}-0.005^{*} \\
(0.003)\end{array}$ & $\begin{array}{c}-0.017^{* *} \\
(0.008)\end{array}$ & $\begin{array}{c}-0.011^{* *} \\
(0.005)\end{array}$ & $\begin{array}{l}-0.017 \\
(0.012)\end{array}$ \\
\hline Afternoon & $\begin{array}{c}0.137^{* * *} \\
(0.019)\end{array}$ & $\begin{array}{c}0.036 \\
(0.032)\end{array}$ & $\begin{array}{c}0.068^{* * *} \\
(0.008)\end{array}$ & $\begin{array}{c}0.035^{* * *} \\
(0.013)\end{array}$ & $\begin{array}{c}0.124^{* * *} \\
(0.014)\end{array}$ & $\begin{array}{c}0.067^{* * *} \\
(0.019)\end{array}$ \\
\hline Evening & $\begin{array}{c}-0.073^{* * *} \\
(0.019)\end{array}$ & $\begin{array}{c}0.005 \\
(0.034)\end{array}$ & $\begin{array}{c}-0.028^{* * *} \\
(0.008)\end{array}$ & $\begin{array}{l}-0.022 \\
(0.014)\end{array}$ & $\begin{array}{c}-0.055^{* * *} \\
(0.013)\end{array}$ & $\begin{array}{c}-0.048^{* *} \\
(0.021)\end{array}$ \\
\hline Xmas & $\begin{array}{c}-0.308^{* * *} \\
(0.052)\end{array}$ & $\begin{array}{c}-0.320 * * * \\
(0.055)\end{array}$ & $\begin{array}{c}-0.161^{* * *} \\
(0.021)\end{array}$ & $\begin{array}{c}-0.163^{* * *} \\
(0.022)\end{array}$ & $\begin{array}{c}-0.212^{* * *} \\
(0.031)\end{array}$ & $\begin{array}{c}-0.213^{* * *} \\
(0.031)\end{array}$ \\
\hline Easter & $\begin{array}{c}-0.140^{* * *} \\
(0.049)\end{array}$ & $\begin{array}{c}-0.150^{* * *} \\
(0.044)\end{array}$ & $\begin{array}{c}-0.089^{* * *} \\
(0.021)\end{array}$ & $\begin{array}{c}-0.094^{* * *} \\
(0.019)\end{array}$ & $\begin{array}{c}-0.111^{* * *} \\
(0.030)\end{array}$ & $\begin{array}{c}-0.119^{* * *} \\
(0.030)\end{array}$ \\
\hline Bmibaby & $\begin{array}{c}-0.857^{* * *} \\
(0.085)\end{array}$ & & $\begin{array}{c}-0.468^{* * *} \\
(0.028)\end{array}$ & & $\begin{array}{c}-0.725^{* * *} \\
(0.056)\end{array}$ & \\
\hline MyTravelLite & $\begin{array}{c}-0.257^{* * *} \\
(0.043)\end{array}$ & & $\begin{array}{c}-0.140^{* * *} \\
(0.018)\end{array}$ & & $\begin{array}{c}-0.252^{* * *} \\
(0.028)\end{array}$ & \\
\hline Aer Lingus & $\begin{array}{c}-0.640^{* * *} \\
(0.041)\end{array}$ & & $\begin{array}{c}-0.354^{* * *} \\
(0.016)\end{array}$ & & $\begin{array}{c}-0.513^{* * *} \\
(0.025)\end{array}$ & \\
\hline British Airways & $\begin{array}{c}-0.576^{* * *} \\
(0.055)\end{array}$ & & $\begin{array}{c}-0.312^{* * *} \\
(0.020)\end{array}$ & & $\begin{array}{c}-0.349^{* * *} \\
(0.026)\end{array}$ & \\
\hline $\mathrm{R}^{2}$ & 0.547 & 0.594 & 0.574 & 0.632 & 0.454 & 0.526 \\
\hline Observations & 14,435 & 14,435 & 14,435 & 14,435 & 14,435 & 14,435 \\
\hline
\end{tabular}

Dependent variable: Entropy index, measured with three alternative parameters: 0, 1 and 2, which respectively correspond to models: Entropy(0), Entropy(1) and Entropy(2). Columns labeled FE report the flight code Fixed Effect estimates. ArriveDepart, monthly dummies and route dummies are included, but not reported. Standard errors in parenthesis, clustered by route-week. Coefficients ${ }^{* * *}$ statistically significant at $1 \%,{ }^{* *}$ at $5 \%$ and ${ }^{*}$ at $10 \%$. 


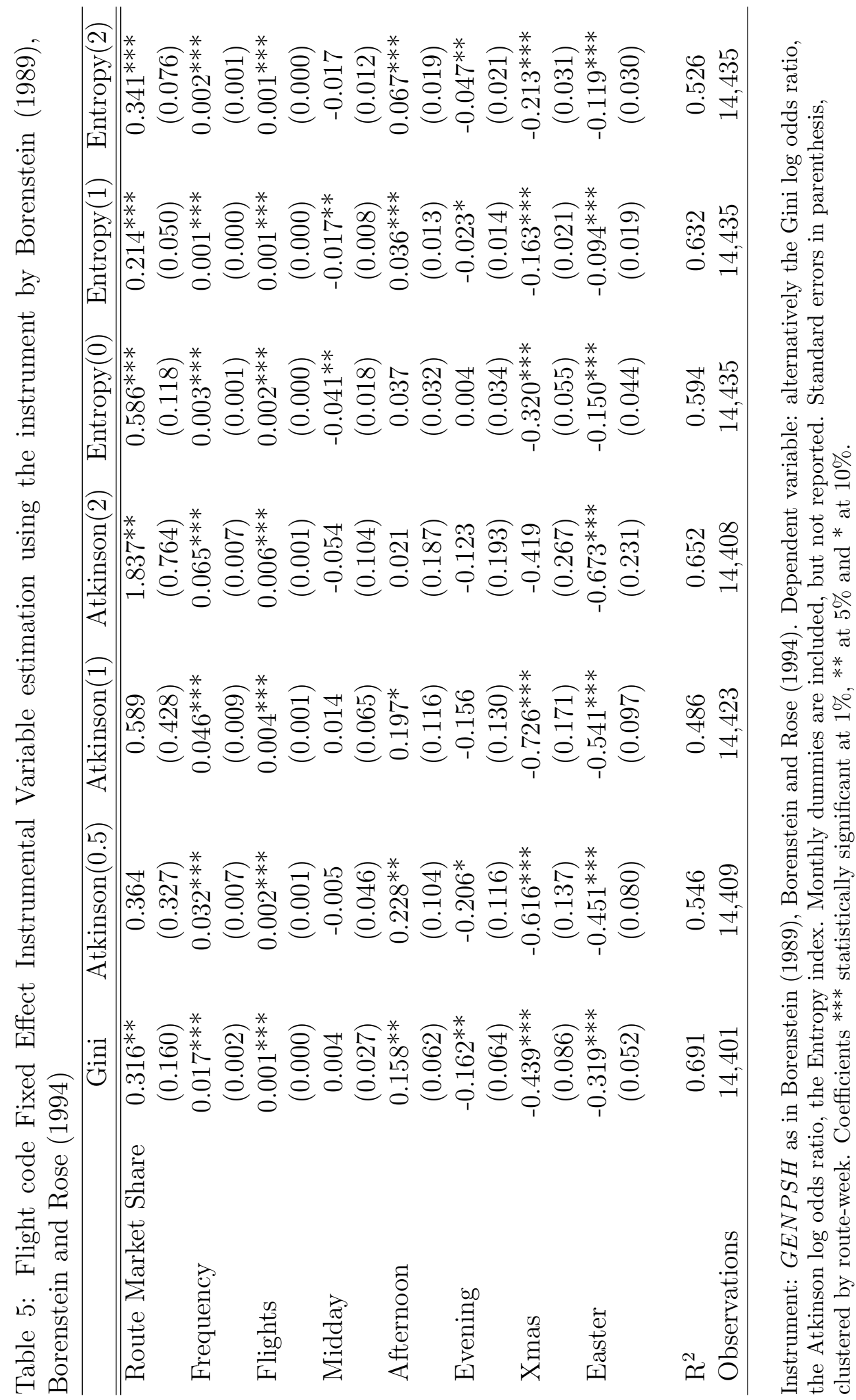




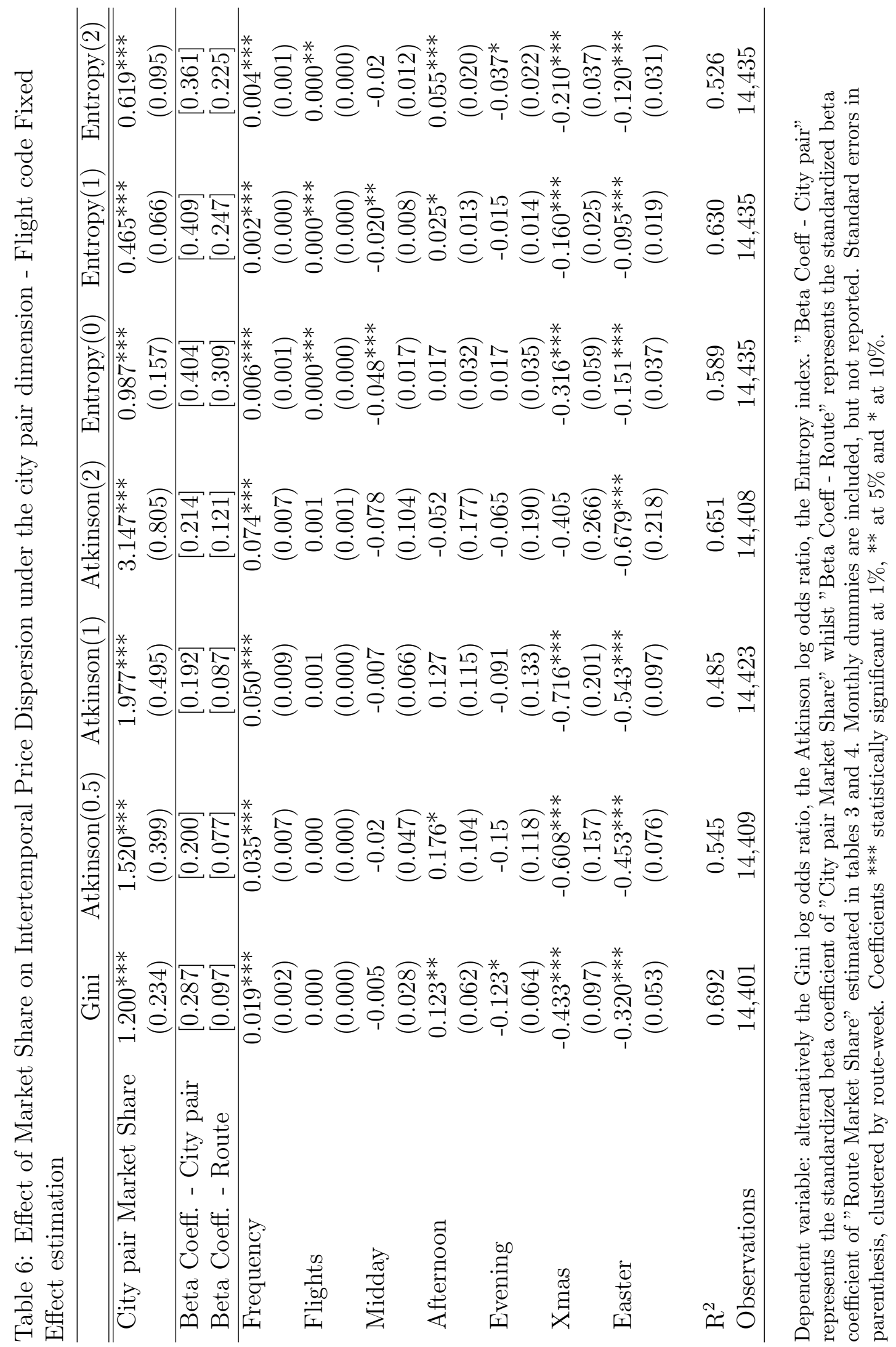




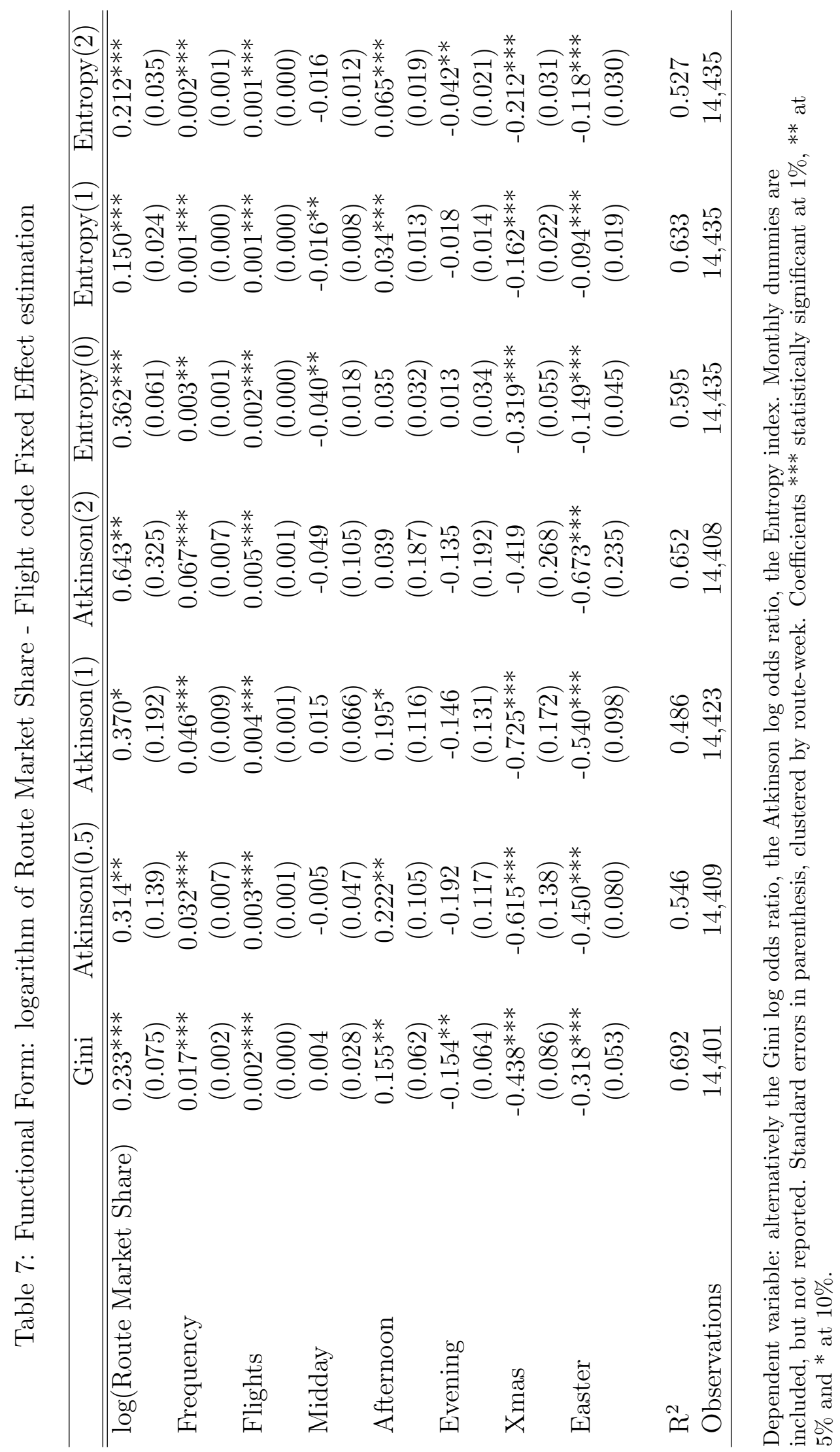




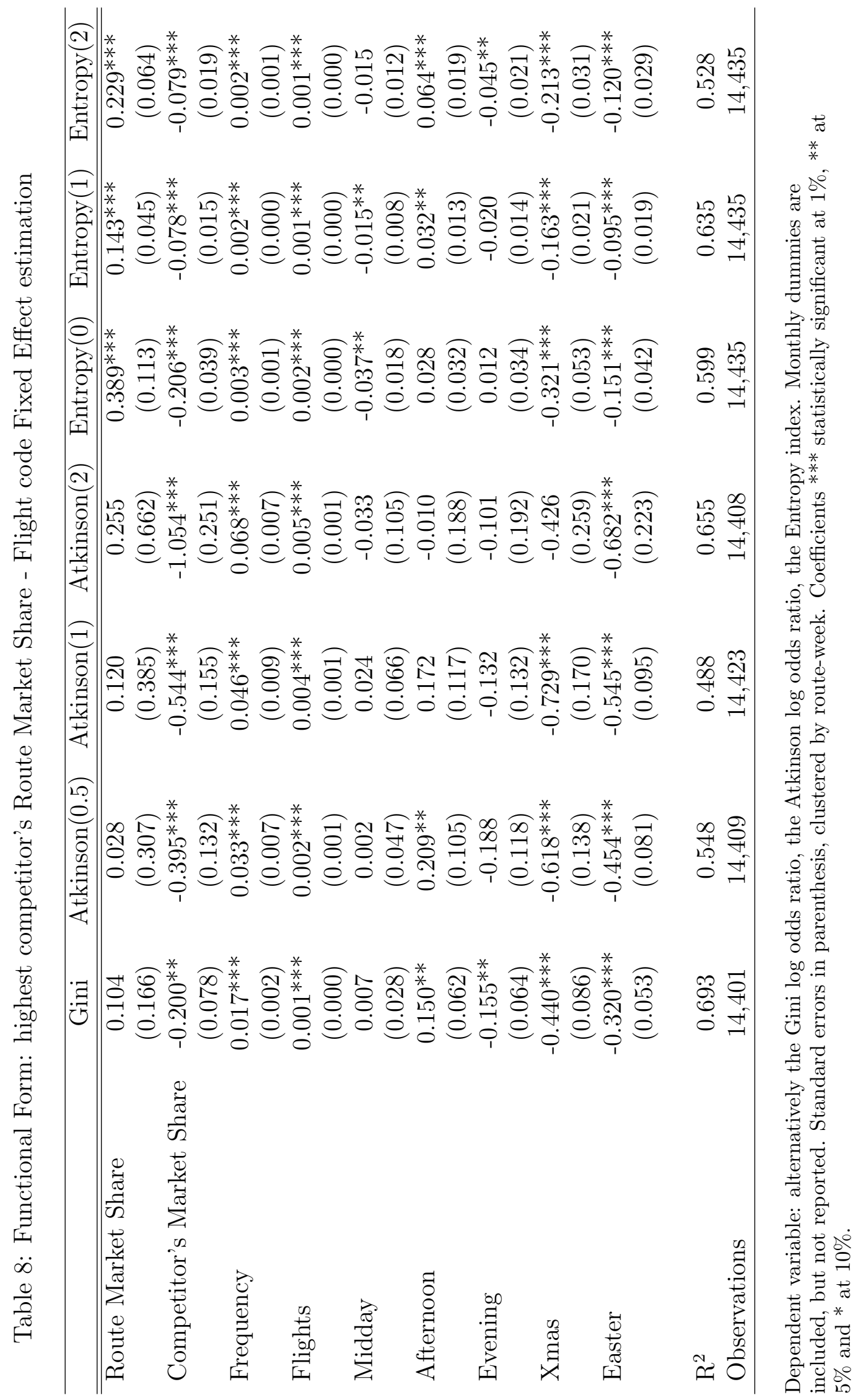




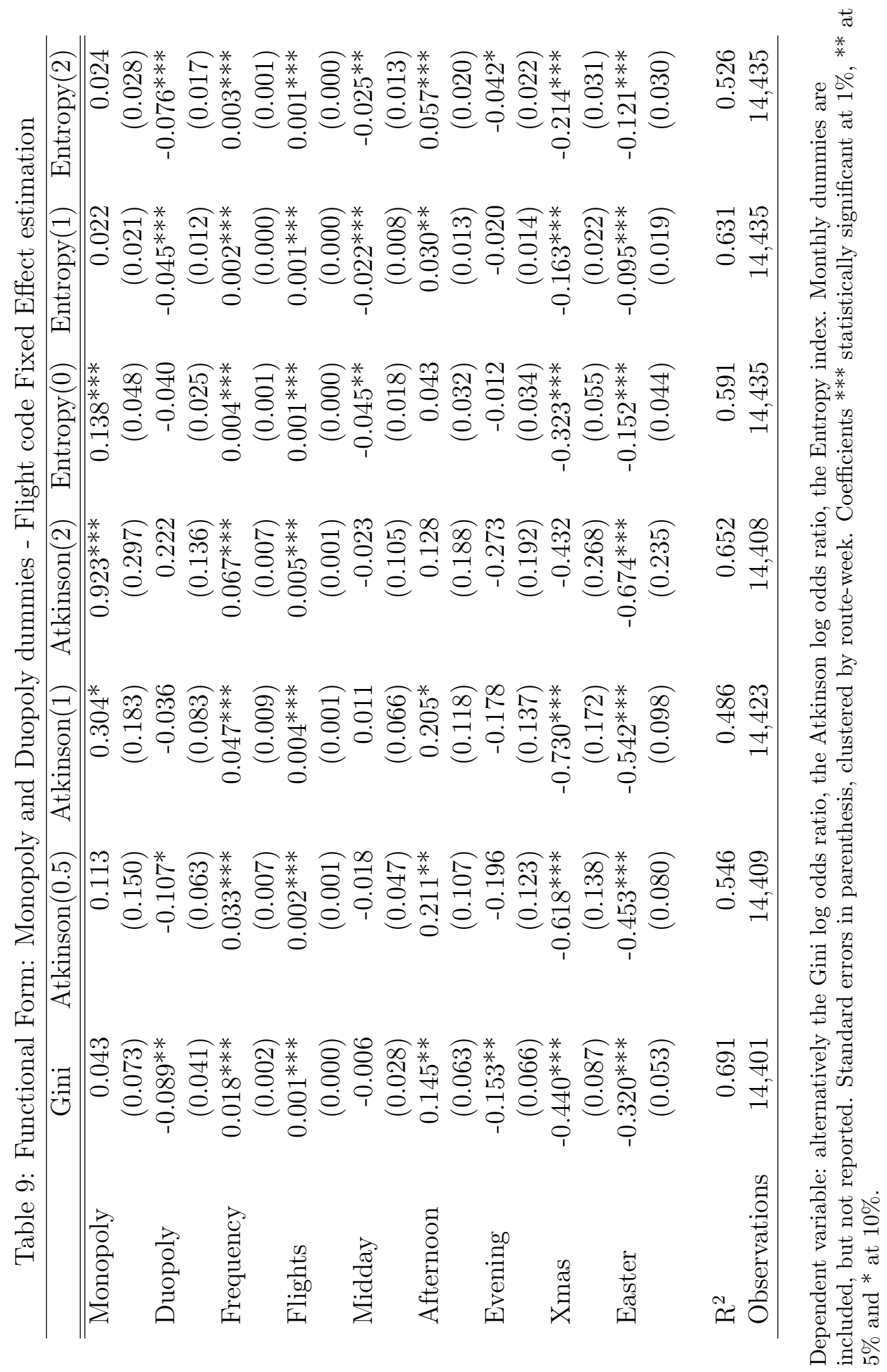




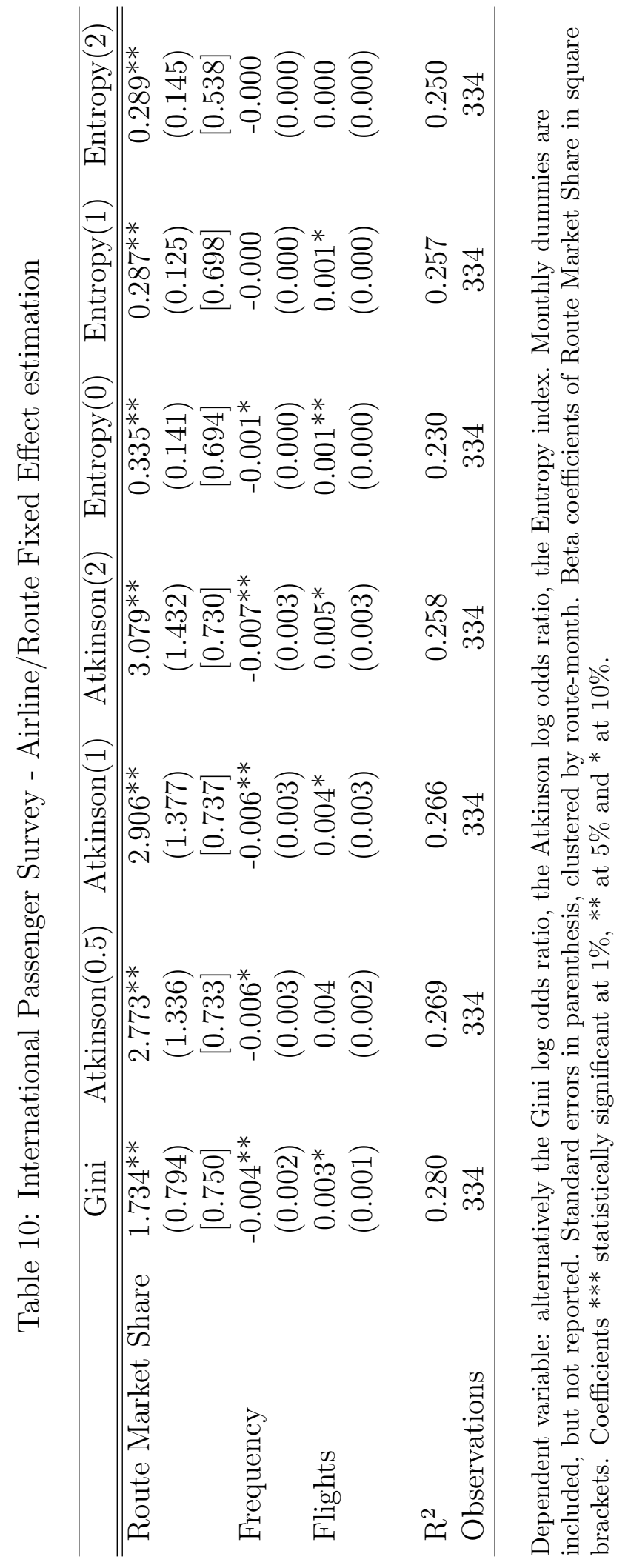

